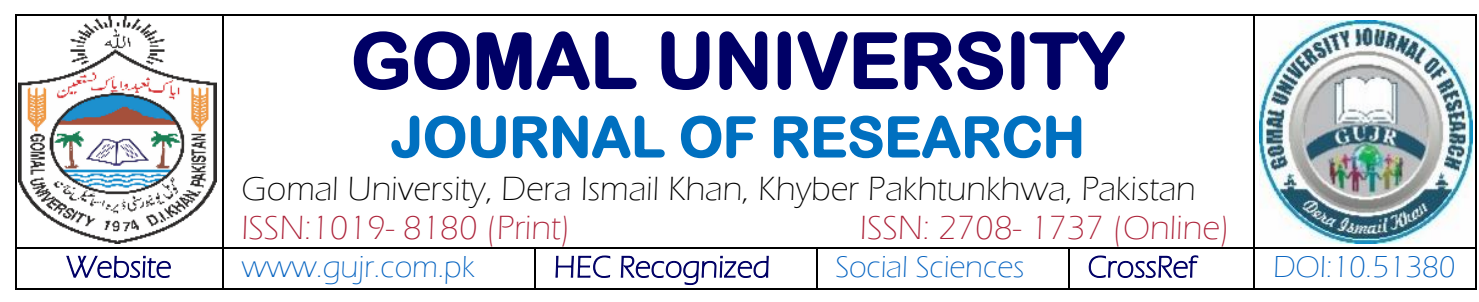

\title{
THE STRATEGIC MANAGEMENT MODEL FOR COVID 19 "A RACE AGAINST TIME": EVIDENCE FROM PEOPLE'S REPUBLIC OF CHINA
}

\author{
Zahid Sarwar' ${ }^{1}$, Muhammad Asif Khan² \& Aaqib Sarwar ${ }^{3}$
}

'School of Business Administration, Dongbei University of Finance \& Economics, Dalian, CHINA 2school of Management, Huazhong University of Science and Technology, Wuhan, P.R. CHINA ${ }^{3}$ School of Economics and Management, The Dalian University Technology, Dalian, P.R. CHINA

\section{\begin{tabular}{l|l} 
KEYWORDS & ABSTRACT
\end{tabular}}

Leadership, Strategic Management Process,

Emergency Decision

Making \& COVID-19

\section{Article History}

Date of Submission:

11-07-2021

Date of Acceptance:

15-09-2021

Date of Publication:

30-09-2021
This article narrates that strategic leadership thinking and quick decisionmaking ability are vital to minimize the negative impact of COVID 19 on the public health and safety. Current outbreak poses serious need to develop a model for tackling the outbreak. The study also argues that the strategic management process and emergency decision-making provide direction to the leadership efforts in ensuring public health and enable scientific allocation of resources during the COVID 19 pandemic. The study presents the strategic management model of COVID 19 by integrating the strategic management process with emergency decision-making model. The study applies the model on People's Republic of China experience with COVID 19 and finds high applicability of proposed model. Moreover, the study argues that other countries can use proposed model to guard the public health and safety by defeating COVID 19. Deloped strategic management model posses a significant practical implications in the current scenarios, as COVID 19 is posing a threat to human race.

\section{(c) 9 \&)}

2021 Gomal University Journal of Research

\begin{tabular}{l} 
Corresponding Author \\
\hline $\mathrm{DOl}$
\end{tabular}

Zahid Sarwar: Zahidsarwar13@gmail.com

https://doi.org/10.51380/gujr-37-03-03

\section{INTRODUCTION}

Globally human beings are suffering from the ongoing outbreak of the COVID-19 pandemic as it reaches two hundred and ten countries. As per the report of WHO, worldwide, 204987 lives were lost to COVID 19 with 2995758 confirmed cases (Organization, 2020). It is the greatest number of deaths and confirmed cases to any pandemic in human history, which makes COVID 19 not only a threat to global economy but even the human race (Bogoch, Watts, Bachli, Huber, Kraemer \& Khan; Wu., Hao, Lau, Wong, Leung, Cowling \& Leung, 2020). The World health organization (WHO) already declared COVID 19 a threat to the world. In a situation in which 7.594 billion people's lives (Bank, 2018b) and 80.93 trillion dollars (Bank, 2018a) economy are 
at risk, world leader's skills, abilities, and qualities will be challenged. In pandemic like this, the world's leadership faces a lot of public health and safety and related economic challenges that need additional competencies to overwhelm the situations. To mitigate these challenges, leadership must be ahead of the time in approaches by making quick and data-driven decisionmaking.

In these kinds of situations, leader finds themselves in "Race against time" scenario. Decisionmaking is choosing optimal choice among all available options to achieve requires objectives (Yu \& Lai, 2011). Emergency decision-making (EMD) is a crucial model that serves decision support protocols, sharing information, and cooperation. Gong (2015), Wang, Zeng and Xu (2011), and Zhou, Wu., Xu \& Fujita (2018) studied EDM in unexpected disastrous situations. The People's Republic of China is first country to hit COVID 19. In short period, they managed to control outbreak of COVID 19 with quick data-driven decisions and strategic management mechanisms. This gives us research gap to thoroughly look into their action plans of mitigating the impact of COVID 19and extent the literature on COVID 19 and emergency decision making (EDM) by answering the several questions as emerged from the uncertain situation like: What strategic mechanism and data-driven decision China made to control the COVID 19?, How they implement their plans to control the spread of COVID 19? And How fast do they make those plans?

\section{LITERATURE REVIEW}

Health workers usually interact with patients with contagious outbreaks, severe sickness, and they are their routine jobs. Still, the outbreak of COVID-19 and treating patients infected with the virus may be stressful, in actuality. Originally, COVID-19 was formulated as a respiratory lung-related viral infection that enhances the probabilities of unintentional infection through immediate contact with patients, and it is further thought to be significantly more extremely feasible to catch than was firstly thought (Hamzah, Yazid \& Shamsudin, 2020; Mustapha, Yazid \& Shamsudin, 2020) On other hand, doctors may opinion considerate for COVID-19 patients as a positive experience, for example, high levels of personal satisfaction, positive feelings, and achievement. Here, some researchers reported that doctors had taken it as a challenge, are found more committed than ever before, and have carried out extensively long-hour duties in hospitals to treat people infected with COVID-19 (Bavel, Baicker, Boggio, Capraro, Cichocka, Cikara \& Druckman, 2020), which shows doctors' high level of commitment to the humans, humanity, and society. The considerable exposure to infected patients is certainly related to job stress and burnout and can significantly influence the Organizational Commitment of doctors with duties and responsibilities. In this study, based upon the existing trends, we theoretically explore the evidence from China and develop model that will be highly applicable to tackle the pandemic.

The decision theory analysis is a multistage normative model of optimal alternatives among all alternatives (Kunreuther \& Schoemaker, 1981). Three types of decisions are Routine, tactical, and strategic (Bauer \& Gergen, 1968). Strategic decisions are related to complexity and require strategic thinking. Strategic thinking has core importance in strategic management process. It is using different analytical tools and decision-making processes to achieve the objectives by tackling future challenges (Pollard \& Hotho, 2006). Strategic management processes, such as strategic planning, formulation, implementation, and evaluation, are usually associated with achieving long-term objectives (Pfeffer, 1982; Wack, 1985). In crises like COVID 19, seconds 
are more valuable than minutes, minutes are more valuable than hours, hours are valuable than weeks, weeks are more expensive than months, and months are valuable than years. On December 31st China reports its first COVID 19 case; afterward, number of new confirm COVID 19 cases becomes exponential till February 19th when for first time, a drop in new cases was noticed, which makes China first country that successfully controls the spread of COVID-19. Based on People's Republic of China's experience on successful mitigation of COVID 19, model or framework is needed to reference other countries. This study proposes a framework (figure 1) by integrating strategic management process with emergency decision-making (EDM) to fill gap.

To better understand the proposed framework and outbreak of COVID 19 in different situation, keeping in view existing trends, this study analyzes strategic choices, and pace at which these choices were formulated and implemented empirically by Chinese leadership as shown in graphs 1 and 2.

\section{RESEARCH METHODOLOGY}

This study explores the critical phenomenon of the COVID-19 and Chinese measures to contain spread of it. This study main objective is to establish the fromwork that can be use to as a blueprint to contain the virus and minimize the economic and human life loss. This study uses mixed method to analyze the subject of the study. Fisrt, this study collect the information about Chinese strategies to scrub spread of virus. Fot this, we obtained the information from Chinese official sources such as CGTN and Xinhua. Moreover study also collect the information from already published reseach articles. For this, we searched different data bases such as Google Scholar, SAGE Publications, and JSTOR. Based on the obtained information, we categorize The Chinese government strategies into strategic management and emergency decision making framework. The details of this integrated framework is discussed below starting from heading of "Strategic management and EDM in COVID 19. In the later step, we collect the qualitative data from WHO and World Bank website as did by Khan, Khan and Siddique (2021). Based on the collected data, we used MS Excel for analysis. We assess the applicability of the framework by using this data. This applicability is discussed under the heading of the "Proposed Model Applicability".

\section{ANALYSIS AND DISCUSSIONS}

In December 2019, outbreak of a novel coronavirus COVID-19 struct the world by surprise. This outbreak emerged from Wuhan, China, and took the world by storm. Soon this pandemic has become a global threat to human health and the human race. The number of confirmed cases is in the billions and growing at rapid pace. The COVID-19 viruses can also be fatal, with a mortality rate of around 3\%.1 Onset of severe disease can result in the death due to massive alveolar damage and progressive respiratory failure. Managing and containing the spread of the contagious virus is a management and leadership race against time. On the one hand, they have to stop the spread of the virus and formulate strategies to successfully cure the infected patients. On other hand, they had to manage and allocate the resources wisely and effectively to mitigate my virus's damage. Hence, this study highlight standing of strategic management processes to develop the model of eliminating the spread of COVID-19. Strategic management is a process of scanning the environment to formulating objectives \& strategies also implement and control these strategies to achieve objectives (Chon \& Olsen, 1990; Smith, Arnold \& Bizzell, 1991). 


\section{Strategic Management \& EDM in COVID-19}

Hence, strategy formulation, implementation, and control are three essential steps involve in strategic management process. Emergency decision-making (EMD) is a process of six stages. These stages include defining a problem, setting goals, designing a project, selecting a project, implementing, and providing feedback (Yu \& Lai, 2011). According to Thomas (1984), the early stages of the EDM provide detailed insight into problem identification, while the strategic management process stresses more on implementation and monitoring. Moreover, EDM is a one-time process, while the strategic management process is more cyclical. Moreover, EDM is a short-term process, while strategic management process long term (Thomas, 1984). Therefore, our study integrates these two models to proposed one that suits and is applicable in current COVID 19. Study integrated strategic management process with emergency decision-making (EDM) and proposed a model based on the People's Republic of China experience, as shown in figure 1. This study proposes the model or framework for the reference of other countries as the world health organization (WHO) declares COVID 19 a global threat. The series of the actions, decisions, and strategies Chinese leadership formulates, implement, and control to minimize the negative impact of COVID 19 on the public health and security are now explained in great detail.

\section{Leadership Mission}

The COVID-19 pandemic carriage is one of the supreme intimidations in recent human history as the virus has spread rapidly worldwide, affecting lives and livelihoods of billions. According to the report of WHO, this pandemic infected more than billions of confirmed cases across the globe. The scale of the COVID-19 is not limited to any country or area. It has already spread globally and become a threat to the economy and human race. Eastern Mediterranean Region alone, with considerable differences in scale and progression of pandemic in different earlier implementations was associated with better outcomes (Gibney, 2020). In countries like China, Germany, and New Zealand, leaders have been praised for leadership qualities and strategic thinking. Their quick decision-making successfully helps them containing spread of COVID-19. In these overwhelming situations, these visionary leaders' actions are required from different leading parameters, such as mask mandate, lock-down, and more, have helped them manage the spread and treat infected patients (Alsharaydeh, Rawashdeh, Saadeh, Obeidat, \& Obeidat, 2020).

In December 2019, Wuhan authorities reported that pneumonia of unknown etiology creates a chaotic situation across the country, later named COVID 19. It adds to chaos when a committee led by Dr. Zhong Nanshan reports the first human-to-human transmission of the COVID 19 in Guangdong (Lin, Zhao, Gao, Lou, Yang, Wang, Cai, Wang \& Yang, 2020). Panic among the general public appeases when President Xi announces the top leadership mission "Fight the virus by guarding public health and safety" on January 20thof 2020. It was a successful start to the war against COVID 19 because the mission statement gives direction to the leadership and their strategies and helps them achieve public confidence. In this connection, it also serves a particular purpose that further helps stay on track to achieve that purpose, and is the basis for evaluation.

\section{Information Collection about COVID-19}

The information collection is significant and challenging step in formulating strategies against COVID-19. This step is challenging because COVID 19 is a new strain of virus. Medical doctors 
and other experts in the field of virology are unfamiliar with the COVID 19. Municipal health commission of Wuhan, National Health Commission of China (NHC), Chinese Center for the Disease Control and Prevention (CDC), and Wuhan Institute of Virology (WIV) investigate unknown pneumonia and collect all possible information regarding it. On January 4th, NHC issue initial guidelines for medical personnel regarding the treatment of patients. NHC also issues safety instructions to public. CDC isolates the first novel coronavirus strain on January 7th. NHC experts announce the coronavirus is the cause of pneumonia. Wuhan Institute of Virology (WIV) develop test kits. With the help of CDC and WIV, the Chinese Academy of the Sciences (CAS), a designated CDC agency, reports the genome sequence of COVID 19 (Xinhua, 2020a).

\section{Information \& Strategic Objectives}

This step involves analyzing and collecting information about resources. COVID-19 is a virus disease. Thus essential types of the resources are human resources, financial resources, physical resources, and operational structure. The human resources mainly include medical doctors and nurses, physical resources include medical equipment such as personal protective equipment and ventilators, and functional structure means hospitals. Based on information about COVID 19 and resources, Chinese leadership develops strategic choices and set objectives to achieve the primary purpose of guarding public health and safety by defeating the COVID 19. In this linking, according to official sources and the data available on COVID 19, the top objectives of Chinese leadership are: Control the spread of COVID 19, better treatment and treatment for all, appropriate resource allocation and guarantee medical supplies, protection of frontline medical workers, ensure supply of the households, public awareness and unity and collaborations with WHO and international community along with other suitable measures (Editors, 2020; Xinhua, 2020a).

\section{Strategic Implementation}

Public health and safety are the Chinese leadership priority during the outbreak of COVID 19. In a disastrous situation like this, pandemic guarding public health and safety is always raced against time. Top leadership has to take a data-driven decision quickly because of limited time to respond. The Chinese strategies leadership uses to ensure public health and safety are now discussed in detail. In China, inception of COVID 19 takes place at spring festival eve. Usually, China reports a massive number of people mobilization on this eve. Since, Dr. Zhong Nanshan announces direct and indirect human-to-human transmission (Lin et al., 2020), halting the spread of COVID 19 is a challenge. Using a face mask, wash hands for 30 seconds, use sanitizer to wash hands are some examples of guidelines NHC announces for public health safety. The only way to stop the spread of virus is by separating infected people from non-infected people. Social, physical distancing, freeze epicenter, suspension of intracity transport, 14 days home isolation, strict community level isolation, temperature measure at community level, growing testing capabilities, shortening testing life cycle, and dividing a population into low, medium high-risk zones are strategies used by Chinese leadership to halt the spread of COVID 19 (Editors, 2020).

The sudden and unexpected inception of COVID 19 put severe burden on hospitals, which leads to treatment delays. Building two hospitals of 2000 beds within ten days, converting public places and exhibition centers into temporary hospitals of 100,000 beds, involving traditional Chinese medicine recourses, and free treatment for everyone helped to improve the treatment methods and capacity (Editors, 2020). Increasing the production of medical equipment (daily 
test kits supply is 350000), the personal protective equipment PPE's (Protective suits increase 21,000 to 270,000, KN95 from 72000 to 562,000) and using People's liberation army (PLA) cargo plan help to achieve the objective enough medical supplies (Editors, 2020). In this regard, keeping safe the frontline medical workers is a top priority of leadership during the war against viruses. The National Health Commission (NHC) continuously analysis the contagious ability of COVID 19 and, from time to time, provide manuals and training to the medical workers about how to use the personal protection equipment. Finally, the medical worker's infection rate was brought to zero (Editors, 2020). Thus, among 40000 medical workers, no one gets infected by COVID-19.

Central leadership designated different departments to ensure ample availability of households at stable prices. The department stresses using online mobile applications to ensure contactless distribution of households at the doorsteps. From time to time, since the inception of COVID 19 until recently, National Health Commission of China (NHC) announced guidelines to inform public about COVID-19. The leadership of China uses mainstream media, social applications, and official websites to inform public about COVID-19. To keep unity among public leadership of China promotes campaigns, "war to protect Hubei," war to protect Wuhan and "jiayouzhonggou Jiayou Wuhan" on mainstream media and social sites (Editors, 2020). Chinese leadership invites WHO to Wuhan to examine situation about virus and, on January 12th national health commission (NHC) shares genome sequence of COVID-19 with world health organization (WHO) (Xinhua, 2020a). President Xi contacts French president and German Chancellor and shows a willingness to work in collaboration with the international community to control the spread of COVID-19.

\section{Monitoring \& Control}

This is crucial step to fight COVID-19 because it provides constant feedback for improvements. Central and local leadership formulate committees for continually monitoring and analyzing the situation of outbreak. These committees work as a bridge to pool the different departments. A committee "novel coronavirus prevention and control" consists of 32 government department is an example of it. Other committees of 11 ministerial-level officials, academicians, and experts analyzed the ground-level situations and provided feedback for the improvements (Editors, 2020).

Graph 1 Daily Base New Cases

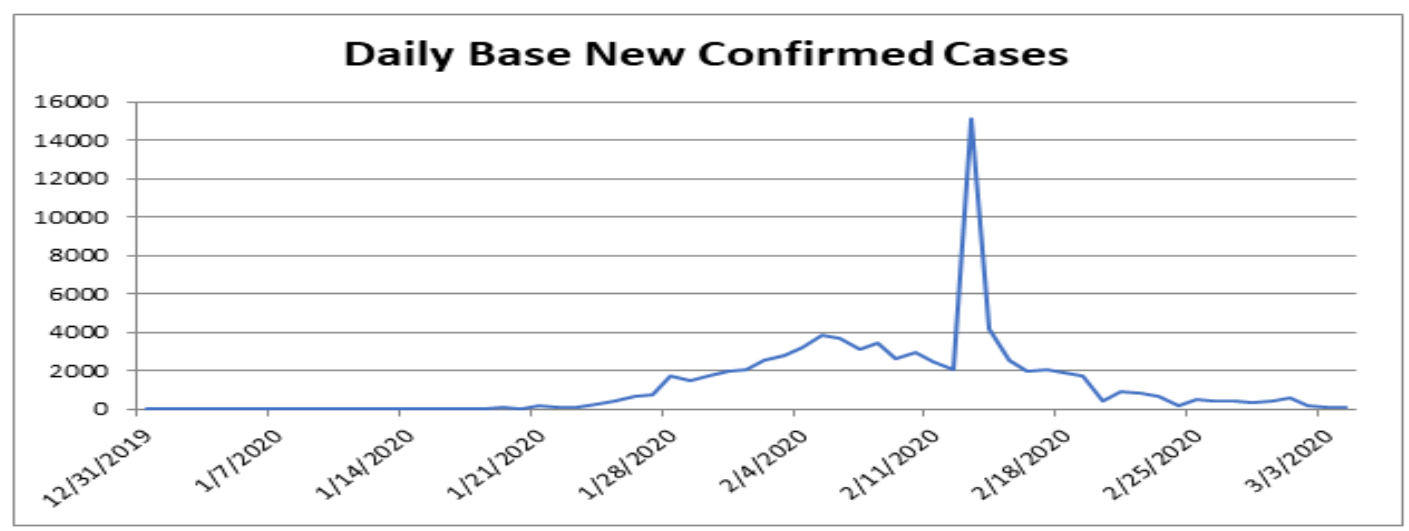


Graph 2 Daily Base Deaths

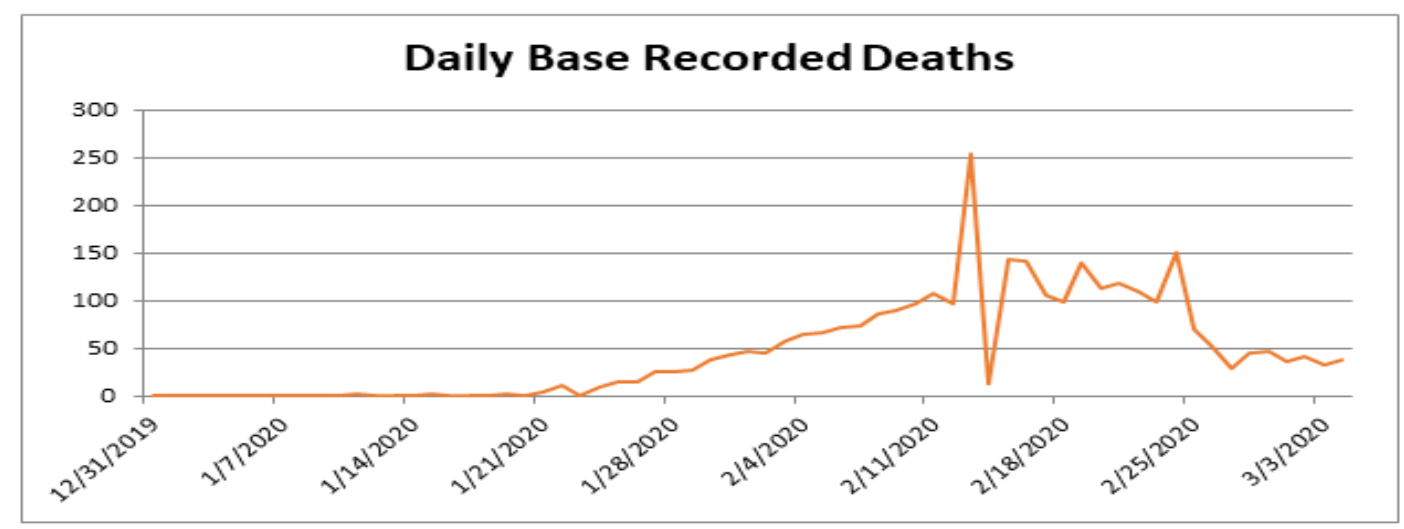

\section{Proposed Model Applicability}

To analyze the applicability of the proposed strategic management model for COVID 19, study thoroughly develops insights into strategies used by the Chinese leadership to fight the virus. The primary goal of the administration was to fight the virus by guarding people's health and safety. The key to success against contagious COVID 19 is to minimize death rate by bringing the daily new confirmed cases to zero. The study obtains the daily base data of new confirmed cases of China from work bank and analyzes it. In China, the life cycle of COVID 19 pandemic was for three months. In an unexpected disastrous situation, appropriately and scientifically allocation of resources is very important to fight it. Forty-six thousand medical workers across the country, including 4000 army medical workers, reach the epicenter to appease the stress on medical units. In early stages of information collection and strategy formulation, the rate of new cases and deaths increased daily, as shown in graphs 1 and 2. After January 2oth, at the stage of strategic implementation, president Xi announces war against covid 19. During this, the number of new cases becomes exponential, and death rate was rising too till February 15th, when a constant drop in new cases was observed, as shown in graphs 1 and 2. At this point, Chinese leadership observes that strategies they are implementing to guard public health and safety are working successfully. Soon after this, on March 4th China reports zero new confirmed cases with the lowest death rate shows the applicability of the strategic management model of COVID-19.

\section{CONCLUSION}

Unexpected outbreaks like this always challenge leadership qualities of quick decision-making, strategic thinking, and inspiring followers. These are essential qualities to tackle the outbreak of COVID 19. Chinese leadership took a swift and effective decision in early stage of COVID-19. Freezing the epicenter of 10 million people was a game-changing decision against the fight of COVID 19 (Xinhua, 2020b), even though international community criticizes Chinese leadership for this decision. All concerned departments such as NHC, CDC, WIV, and CAS work around the clock to be familiar with COVID 19 so that they can provide data for strategy formulation against COVID 19. Currently, the entire world is suffering from COVID 19. Since day one, when authorities in Wuhan announce unknown pneumonia, the Chinese leadership is working in collaboration with the world health organization (WHO) so that the international community is 
well aware of the outbreak of COVID-19 and take proactive measures to control the possible spread of COVID-19 in their respective countries. Total confirmed cases in world are 2995758, with 204987 deaths (Organization, 2020). There is a need to explore the People's Republic of China's experiences with COVID-19 and formulate a framework for reference of other countries to mitigate the impact of COVID-19. Henceforth, based on China's experience with COVID-19, this study integrates the strategic management process with the emergency decision making to extend the knowledge on COVID-19, strategic management, and data-driven decision making. Consequently, the practitioner can also use this framework in future unexpected outbreaks of the virus.

\section{REFERENCES}

Alsharaydeh, I., Rawashdeh, H., Saadeh, N., Obeidat, B., \& Obeidat, G. (2020). Challenges and solutions for maternity and gynecology services during the COVID-19 crisis in Jordan. 150 (2), 159-162.

Bavel, J., Baicker, K., Boggio, P. S., Capraro, V., Cichocka, A., Cikara, M., \& Druckman, J. N. (2020). Using social and behavioural science to support COVID-19 pandemic response. 4(5), 460-471.

Bank, W. (2018a). GDP (current US\$). Bank, W. (2018b). Population, Total. Bauer, R. A., \& Gergen, K. J. (1968). The study of policy formation.

Bogoch, I. I., Watts, A., Bachli, A., Huber, C., Kraemer, M. U., \& Khan, K. (2020). Pneumonia of Unknown Etiology in Wuhan, China: Potential for International Spread Via Commercial Air Travel. Journal of Travel Medicine.

Chon, K. S., \& Olsen, M. D. (1990). Applying the strategic management process in management of tourism organizations. Tourism Management, 11, 206-213.

Editors, T. O. (2020). China's Fight Against COVID-19, China, Tsinghua University, Peking Union Medical College.

Gibney, E. J. N. (2020). Whose coronavirus strategy worked best? Scientists hunt most effective policies. 581 (7806), 15-17.

Gong, Q. S. (2015). Emergency Decision-supporting System Based on Multi-Agents Negotiation. Proceedings of 5 th International Asia Conference on Industrial Engineering and Management Innovation, 2015. Springer, 49-53.

Hamzah, A., Yazid, M. F., \& Shamsudin, M. F. (2020). Post covid-19: What next for real estate industrial sector in Malaysia? 1(1).

Khan, M. A., Khan, M. W., \& Siddique, A. (2021). Is climate indicator affects transmission of covid-19 pandemic: climatic impacts on covid-19 transmission. Gomal University Journal of Research, 37(1), 35-42.

Kunreuther, H. C., \& Schoemaker, P. J. (1981). Decision A nalysis for Complex Systems: Integrating Descriptive and Prescriptive Components. Knowledge, 2, 389-412.

Lin, Q., Zhao, S., Gao, D., Lou, Y., Yang, S., Wang, M. H., Cai, Y., Wang, W. \& Yang, L. (2020). A conceptual model for the coronavirus disease 2019 (COVID-19) outbreak in Wuhan, China with individual reaction and governmental action. International journal of infectious diseases, 93, 211-216.

Organization, W. H. (2020). Coronavirus (COVID-19) [Online]. Available online: https:// covid19.who.int/. 
Mustapha, N. N., Yazid, M. M., \& Shamsudin, M. F. (2020). How airline industry may rise post covid-19 pandemic. 1(1).

Pollard, D., \& Hotho, S. (2006). Crises, scenarios and the strategic management process. Management Decision.

Smith, G. D., Arnold, D. R., \& Bizzell, B. G. (1991). Business strategy and policy: Cases, Houghton Mifflin College Div.

Thomas, H. (1984). Strategic decision analysis: applied decision analysis and its role in the strategic management process. Strategic Management Journal, 5(2), 139-156.

Wack, P. (1985). Scenarios: shooting the rapids. How medium-term analysis illuminated the power of scenarios for shell management.

Wang, L., Zeng, J., \& Xu, L. (2011). A decision support system for substage-zoning filling design of rock-fill dams based on particle swarm optimization. Information Technology and Management, 12, 111.

Wu., P., Hao, X., Lau, E., Wong, Y., Leung, S., Cowling, B. J., \& Leung, G. M. 2020. Real-time tentative assessment of epidemiological characteristics of novel coronavirus infections in Wuhan, China, as at January 22nd 2020. Eurosurveillance, 25, 2000044.

Xinhua. (2020a). China publishes timeline on COVID-19 information sharing, international cooperation.

Xinhua. (2020b). In unprecedented move, China locks down megacity to curb virus spread [Online]. People's Daily.

Yu, L., \& Lai, K. K. (2011). A distance-based group decision-making methodology for multi-person multi-criteria emergency decision support. Decision Support Systems, 51, 307-315.

Zhou, L., Wu., X., Xu, Z., \& Fujita, H. (2018). Emergency decision making for natural disasters: An overview. International journal of disaster risk reduction, 27, 567-576. 